$\phi_{a}=$ asymptotic value of $\phi$ at large values of $\theta$ (or $\sqrt{M}$ )

$$
\begin{aligned}
& \text { Subseripts } \\
& \begin{array}{ll}
A= & \text { species } A \\
B \quad= & \text { species } B \\
G \quad= & \text { gas phase } \\
i= & \text { to gas-liquid interface } \\
L \quad= & \text { to liquid phase } \\
o \quad= & \text { in film theory, the bulk liquid } \\
& \text { core; in penetration theory, } \\
& \text { the liquid at the start of a } \\
& \text { contact time interval }
\end{array}
\end{aligned}
$$

\section{Superscripts}

- = physical absorption, in which no chemical reaction occurs

\section{LITERATURE CITED}

1. Brian, P. L. T., Sc.D. thesis, Mass, Inst. Technol., Cambridge ( 1956).

2. Bruce, G. H., D. W. Peaceman, H. H.
Rachford, Jr., and J. D. Rice, Am. Inst. Mining Met. Engrs., Petrol. Trans., 198, 79 (1953).

3. Chambre, P. L., and J. D. Young, Phys. Fluids, 1, 48 (1958).

4. Crank, J., and P. Nicholson, Proc. Cambridge Phil. Soc., 43, 50 (1947).

5. Danckwerts, P. V., Trans. Faraday Soc., 46, 300 (1950).

6. Ibid, p. 701 .

7. Douglas, Jim, Jr., Trans. Am. Math. Soc., 89, 484 (1958); see Section 6, Equations 6.16 and 6.17.

8. Friedlander, S. K., and Mitchell Litt, Chem. Eng. Sci., 7, 229 (1958).

9. Gilliland, E. R., R. F. Baddour, and P. L. T. Brian, A.I.Ch.E. Journal, 4, 223 (1958).

10. Hasseltine, E. H., and J. F. Hurley, S. B. thesis, Mass. Inst. Technol, Cambridge (1959).

11. Hatta, S., Technical Reports, Tohoku Imp. Univ., 8, 1 (1928-1929).

12. O'Brien, G. G., M. A. Hyman, and
Sidney Kaplan, J. Math. Phys., 29, $223(1951)$.

13. Peaceman, D. W., Sc.D. thesis, Mass. Inst. Technol., Cambridge (1951).

14. Perry, R. H., and R. I. Pigford, Ind. Eng. Chem., 45, 1247 (1953).

15. Potter, O. D., Trans. Brit. Inst. Chem. Engrs., 36, 415 ( 1958 ).

16. Richtmyer, R. D., "Difference Methods for Initial-Value Problems," pp. 3-27, 93, 98-101, Interscience, New York (1957).

17. Ibid., pp. 101-104.

18. Sherwood, T. K., and R. L. Pigford, "Absorption and Extraction," 2nd ed., pp. 317-339, McGraw-Hill, New York (1952).

19. Sherwood, T. K., and J. M. Ryan, Chem. Eng. Sci., 11, 81 (1959).

20. Van Krevelen, D. W., and P. I. Hoftijzer, Rec. trav. chim., 67, 563 (1948).

Manuscript received April 18, 1960; revision received September 28, 1960 ; paper accepted October $5,1960$.

\title{
Two-Phase Concurrent Flow in Packed Beds
}

\author{
R. P. LARKINS and R. R. WHITE \\ University of Michigan, Ann Arbor, Michigan
}

D. W. JEFFREY

Humble Oil and Refining Company, Baytown, Texas

\begin{abstract}
Pressure drop and liquid saturation accompanying two-phase concurrent flow have been studied in a variety of packings and with gas-liquid systems having a wide range of fluid properties. Two basic flow patterns were observed with nonfoaming systems. Correlations of pressuredrop and liquid-saturation data were obtained in terms of the single-phase friction losses for the liquid and the gas when each flows alone in the bed. Deviations from the correlation with foaming systems are discussed and illustrated with sample data.
\end{abstract}

To design reaction vessels having concurrent two-phase flow of liquid and gas through a catalyst bed a knowledge of certain characteristics of the flow is required. The trickle bed reactor is one such area in which predictions of two-phase pressure drop and liquid saturation, the fraction of void space occupied by liquid, are important.

The purpose of this investigation was to obtain data on two-phase flow in packed beds and to establish a suitable correlation for the prediction of the pressure drop and liquid saturation. To narrow the scope somewhat this discussion will be limited to the correlation of simultaneous downflow of a liquid and a gas and to unconsolidated beds of sufficient pore diameter

R. P. Larkins is with Humble Oil and Refining Company, Baytown, Texas. R. R. White is with the Atlantic Refining Company, Philadelphia, Pennsylvania. that capillary forces are not a major effect. Although some foaming systems will be presented, the main portion of the data is further limited to systems which do not foam.

Piret, Mann, and Wall (9) was the only reference found for two-phase concurrent flow in packed beds. The data for four runs indicated that pressure drops for a given liquid rate and with a gas velocity of $0.46 \mathrm{ft}$. $/ \mathrm{sec}$. were different by a factor of 2 for the countercurrent and concurrent modes of flow. The concurrent pressure drop was observed to be the lower drop.

\section{TWO-PHASE FLOW IN PIPES}

While data on two-phase concurrent flow in packed beds are quite scarce, there has been a substantial interest in pressure-drop data for twophase flow in open pipes for as long as engineers have been designing equipment to vaporize liquids or to condense vapors inside tubes. An extensive bibliography of the early investigations may be found in reference 7 .

The first important correlation for two-phase flow in open pipes was proposed by Martinelli, Boelter, Taylor, Thomsen, and Morrin (7) and was based upon previously reported data as well as data obtained in horizontal pipes of 1-in. diam. and smaller. Martinelli, Putnam, and Lockhart (8) extended the base of the proposed correlation with additional data in the viscous region. The final paper in the series by Lockhart and Martinelli (6) presents the completed correlation in terms of a single curve for each of the four flow mechanisms observed. These mechanisms are as follows: turbulent flow in the gas phase with turbulent flow in the liquid phase; turbulent flow in the gas phase with viscous flow in the liquid phase; viscous flow in the gas phase with turbulent flow in the liquid phase; and viscous flow in the gas phase with viscous flow in the liq- 
Table 1. Systems Investigated

Gas

\begin{tabular}{|c|c|}
\hline Air & Water \\
\hline Air & Water \\
\hline Air & $\begin{array}{l}\text { Water }(2.5 \mathrm{Wt} \text {. \% methyl- } \\
\text { cellulose })\end{array}$ \\
\hline Air & $\begin{array}{l}\text { Water }(0.5 \text { Wt. \% methyl } \\
\text { cellulose }) \uparrow\end{array}$ \\
\hline Air & Water $(0.033 \mathrm{Wt}$ \% soap $) \dagger$ \\
\hline Air & Ethylene glycol \\
\hline Air & Ethylene glycol \\
\hline Natural gas & Kerosene \\
\hline Natural gas & Kerosene * * \\
\hline Natural gas & Lube oil \\
\hline arbon dioxide & Lube oil \\
\hline rbon dioxide & Hexane \\
\hline
\end{tabular}

Column diameter, (in.)

\section{$\dddot{3}_{8}$-in. Raschig rings \\ $3_{8}^{\prime}$-in. spheres \\ ${ }_{\beta}^{3 / \text {-in. Raschig ring }}$}

范-in. cylinders

1/8-in. cylinders

$3_{8}^{\prime}$-in. Raschig rings

$\%_{8}$-in. spheres

$1_{8}$-in. cylinders

3-mm. spheres

3-mm. spheres

3-mm. spheres

3-mm. spheres within the packed test section between the two quick-closing valves. The accuracy of the measurements depends upon the amount of unpacked column between the quick-closing valves and upon the rapidity and uniformity with which the valves are closed. In order to reduce the unpacked volume cups and screens were introduced into each of the $4 \mathrm{in}$. quick-closing valves on the column side. This arrangement allows for uniform packing to within $1 / 2$-in. of the valve gates. The system of weights and cables was so arranged that a single weight closed both valves simultaneously. The weight was lifted and allowed to accelerate for about $3 \mathrm{ft}$. before acting upon the valve handles. The time required to close the valves is calculated to be less than 0.1 sec. A rubber cushion absorbed the major portion of the shock at the end of the weight's travel.

After the test section was allowed to drain, the liquid height above the bottom flange was recorded along with the pressure in the section. The holdup was calculated by multiplying the fraction of the packed length occupied by liquid times the void volume of the test section. The pressure was compared with the average of the top and bottom column pressures recorded with flow to check the proper operation of the quick-closing valves.

The measurement of liquid saturation included a brief comment on the type of flow pattern observed before the quickclosing valves were shut. Two basic flow patterns were observed: homogeneous mode, each local area in the bed is the same and there is no transient behavior; and slugging mode plugs of more dense material travel down the column. The slugs represent a sharp, localized increase in liquid saturation of the type shown in the bottom portion of the column in Figure 1. As gas rates are increased, slugs merge into an ill-defined blurr. A combination of the two basic modes of flow was termed the "transition mode."

Temperatures were measured by copperconstantan thermocouples of the immersion type. The thermocouples were mounted in 1.5-in. lengths of 1/4-in. stainless steel tubing and mounted through the pipe walls at the desired points. Temperatures were measured in the air rotameter outlet and at the bottom of the packed test section.

Schematically the experimental unit having the 2-in. glass column was similar to the 4-in. equipment. The main differences were: over-all pressure drops were taken rather than the middle section, and the unit was not equipped with quick-closing valves which would enable accurate determination of liquid saturation. Hence no liquid saturation data coinciding with pressure-drop data from the 2-in. column are reported.

\section{SYSTEMS INVESTIGATED AND THEIR PROPERTIES}

The systems of fluids and packings selected for this investigation of two-phase pressure drop and liquid saturation were chosen to provide a wide range of the variables used in the correlation of the data. These systems are listed in Table 1, and some of the individual physical prop- 
erties ${ }^{*}$ may be found in Table 2. Several of the individual fluids were also used alone to check existing single-phase correlations.

Most of the columns were packed by settling the particles through liquid while tapping the test section with a rubber hammer. This method of packing the column successfully prevented further settling of the materials during the course of the experiments. The fraction voids were determined with the packing in the test section by introducing measured volumes of water into the test section and measuring the rise in liquid level. The properties of the $3 / 8$-in. ceramic Raschig rings were supplied by the manufacturer. The specific surface was $148 \mathrm{sq}$. $\mathrm{ft} . / \mathrm{cu}$. $\mathrm{ft}$., and the fraction voids was 0.520 .

The $3 / 8$-in. spheres were made of a chemical stoneware material and were not quite spherical. The nominal diameter reported for these spheres was observed to be the average of the longest and shortest dimensions of the particles. The fraction voids was 0.362 and, in the absence of measurements of the specific surface, the particles were assumed to be spherical. The $3-\mathrm{mm}$. spheres were laboratory glass beads and were uniformly spherical and of uniform size. The fraction voids for these beads were determined to be $0.364,0.371$, and 0.375 on three different occasions of packing the column.

The catalyst cylinders investigated were $1 / 8$ in. diameter and $1 / 8 \mathrm{in}$. in length. The fraction voids was measured to be 0.357 , and the specific surface calculated to be 37 I sq. ft $/ \mathrm{cu}$. ft.

\section{DESCRIPTION OF OBSERVED FLOW PATTERNS}

In order to describe the typical variations observed in the flow pattern a constant liquid rate will be discussed as the gas rate is varied from zero to the maximum value. With liquid filling the column a low and constant liquid rate is established in the packed bed. There is sufficient resistance at the bottom of the test section to keep the column full of liquid. As gas is introduced to the column at a very low rate, the liquid saturation is seen to decrease sharply. The formerly clear liquid phase becomes milky or opaque, and small bubbles of gas can be seen in the liquid on close observation. As the gas rate is increased, while the liquid rate is held constant, the pressure drop continues to increase and the liquid saturation to decrease. The gas bubbles increase in size and soon occupy the major portion of the void volume, while the liquid phase takes a path over the particles of the packing material. At first the liquid layer on the packing particles is relatively thick, but it decreases as the gas rate is increased. The flow patterns encountered up to this point are termed the "homo-

* The complete tabulation of properties, data, and results may be obtained from reference 4 . University Microfilms, Inc., Ann Arbor, Michigan.

Table 2. Typical Propenties of Flowing Flums

(Temperature, ${ }^{\circ} \mathrm{F}$., in Parenthesis)

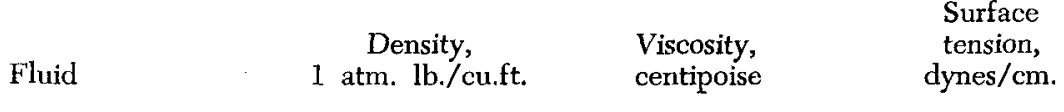

Air

Natural gas

Carbon dioxide

Water

$2.5 \%$ Methocel solution

$0.5 \%$ Methocel solution

$0.033 \%$ soap solution

Ethylene Glycol

Kerosene

Lube oil

Hexane

geneous mode," since the flow is uniform throughout the section. At some point however the flow pattern becomes nonuniform with homogeneous flow at the top of the column and a mode termed the "slugging flow" at the bottom of the column. As the gas rate is further increased, a fully developed slugging flow appears. The slugs appear to be flat plugs of higher density material flowing down the column. When they first appear, they might be about 4 -in. thick and $2 \mathrm{ft}$. apart. As the gas rate is further increased, the slugs become closer and closer together and thinner at the same time. The limit is reached with the slugs blurring together with one another, and the pattern reduces to a poorly defined quiver. Even though the slugs appear well defined when viewed from a distance, close examination reveals only a small increase in the density of the flowing mixture. There is no jump or abrupt change of slope in the plot of pressure drop vs. gas rate for any of the transitions mentioned. If the amount of liquid flowing next to the surface of the packing material is observed during the increase of gas rate, it is seen to decrease steadily until at the limiting gas rate there is a very thin film of liquid on the packing and the voids are filled with a heavy mist.

At very low liquid rates the slugging mode is not observed, and the limiting gas rates produce a homogeneous mode of flow in which the liquid is carried through as a mist, with very little liquid clinging to the surface of the packing material. As the gas is introduced at the very high liquid rate, the liquid becomes milky, but the liquid saturation does not drop sharply. The liquid saturation remains quite high as the gas is increased, even when a tunneling of the gas is observed. Pockets of gas about $1 \mathrm{ft}$. long seem to pass through the interior of the packing without an observable drop in the liquid saturation outside the pockets. At the limiting gas rate a uniform dense mixture of liquid dispersed in gas is observed.

A close examination of the test section reveals instability on at least two scales. In addition to the instability evidenced by the slugging mode of flow a small-scale instability of the magnitude of the particles was observed. An attempt was made to measure the frequency of the two instabilities. The small-scale effect was investigated with the aid of a stroboscope which was used as a standard of comparison. The measurements were very rough, but values between 17 and 33 cycles/sec. were observed. The frequency of this small-scale disturbance seemed to lie within the above range for all of the runs showing the slugging mode of flow. The small-scale disturbance was not observed in the homogeneous mode. The frequencies of the large-scale disturbance vary from zero for the homogeneous mode to values approaching the small-scale disturbance as the slugs become close together. In reporting the data on the mode of flow a code was used to designate four types of patterns as follows: homogeneous, transition, slugs, and close slugs or blur. In addition the estimated spacing of the slugs was recorded $(4,5)$.

A new form of instability was observed in the test section when foaming occurred at low values of the twophase pressure drop. Pressure surges as high as $\pm 40 \%$ of the average value of the pressure drop are reported in the case of kerosene and natural gas. These surges were found to have a reproducible magnitude and frequency. The time between peaks was of the order of magnitude of 5 or $10 \mathrm{sec}$. and varied with the flow rates. The observation of pressure surges was accompanied by a filling and emptying of the column with foam. The column appeared to fill with foam as the pressure drop was observed to increase. The foam then seemed to collapse and be swept from the column in a wave- 
Table 3. Sample Processed Data for Water on ${ }^{3}$-In. Raschig Rings in 4-In. Pipe

\begin{tabular}{|c|c|c|c|c|c|c|c|}
\hline $\begin{array}{c}\text { Run } \\
\text { num- } \\
\text { ber }\end{array}$ & $\begin{array}{l}\text { Liquid } \\
\text { rate, } \\
\text { lb./(sq. } \\
\text { ft.-min.) }\end{array}$ & $\begin{array}{c}\text { Air } \\
\text { rate, } \\
\text { lb./(sq. } \\
\text { ft.-min. })\end{array}$ & $\begin{array}{c}\text { Average } \\
\text { pressure, } \\
\text { lb./sq. in. } \\
\text { gauge }\end{array}$ & $\begin{array}{c}\text { Pressure } \\
\text { drop, } \\
\text { lb./sq. } \\
\text { in./ft. }\end{array}$ & $\begin{array}{c}\text { Column } \\
\text { temper- } \\
\text { ature, } \\
{ }^{\circ} \mathrm{F} \text {. }\end{array}$ & $\begin{array}{c}\text { Liquid } \\
\text { viscosity, } \\
\text { centipoise }\end{array}$ & $\begin{array}{c}\text { Liquid } \\
\text { satu- } \\
\text { ration, } \\
\%\end{array}$ \\
\hline 5 & 2,458 & 0 & 17.29 & 2.321 & 76.0 & 0.901 & 100.0 \\
\hline 23 & 1,365 & 20.14 & 13.43 & 3.083 & 72.0 & 0.950 & 32.3 \\
\hline 28 & 1,365 & 80.98 & 30.23 & 5.940 & 76.0 & 0.900 & 15.0 \\
\hline 57 & 2,731 & 13.08 & 26.58 & 6.091 & 59.0 & 1.142 & 47.0 \\
\hline 63 & 2,731 & 78.85 & 53.65 & 10.377 & 70.0 & 0.975 & 26.6 \\
\hline 86 & 97.93 & 21.47 & 2.82 & 0.802 & 79.0 & 0.870 & 9.9 \\
\hline 90 & 97.93 & 80.62 & 9.53 & 2.176 & 76.0 & 0.901 & 4.8 \\
\hline 160 & 0 & 103.26 & 11.63 & 2.391 & 59.0 & 1.000 & 0 \\
\hline
\end{tabular}

like motion with a corresponding decrease in pressure drop. The surging phenomenon was observed in fairly narrow ranges of the experimental variables, disappearing at low liquid and gas rates and becoming small in magnitude at high gas rates.

The form of instability observed in the foaming kerosene systems was also observed in tests with $0.50 \%$ solution of foaming Methocel on $1 / 8-$ in. cylinders. The phenomenon was found to occur near the lower limit of rates which could be measured in the experimental equipment.

The surges which have been described are felt to be a definite function of the foaming system employed and probably represent a balance between the rate of emulsification and the pressure difference acting upon the foam. As the foam begins to build up, the rates are at their highest values and effect the maximum shear. The foam filling the pores causes the pressure drop to increase across the bed when constant feed rates to the column are maintained. At some point the restriction of flow and the forces on the foam combine to reduce the foaming tendency and force the foam to break. The cycle is then able to repeat itself as the pressure drop decreases and the flow is unrestricted.

Without a more complete understanding of the mechanism of foaming no precise definition could be made. For instance the foaming and large magnitude surges were apparent with fresh Methocel solutions but disappeared as the solutions aged. Also two kerosenes (of same origin but produced a year apart) with seemingly identical properties, even in surface tension, had widely different foaming properties; one produced large pressure surges, while the other kerosene had less foaming and produced only slight pressure surges.

\section{DESCRIPTION OF TABULATED PROCESSED DATA}

For a fixed geometry and system of fluids the independent variables which affect pressure drop and liquid saturation are the flow rates of each fluid and the temperature and pressure levels. Temperatures were not varied widely and were near the ambient level during the laboratory work. Of the remaining variables flow rates were varied extensively, while the pressure level was limited to a maximum of 90 lb./sq. in. gauge by the equipment. A sample of the processed data is shown in Table 3. The runs shown are for air and water on $3 / 8-i n$. Raschig rings in a 4-in. pipe.

The liquid and gas rates are based on the open-pipe area and are reported in pounds per square foot per minute. The pressure and pressuredrop data were obtained from two taps in the central portion of the column shown in Figure 1. Data from the top and bottom sections of the column were found to check that from the central section. The temperature in Table 3 was measured at the bottom of the test column. The change in temperature through the column was neglected, since the heat capacity of the liquid is much higher than that of the gas. The liquid viscosity was based on the bottom column temperature. The average liquid saturation was obtained by dividing the liquid holdup by the total void volume in the packed column. The total void volume was calculated from the dimensions of the

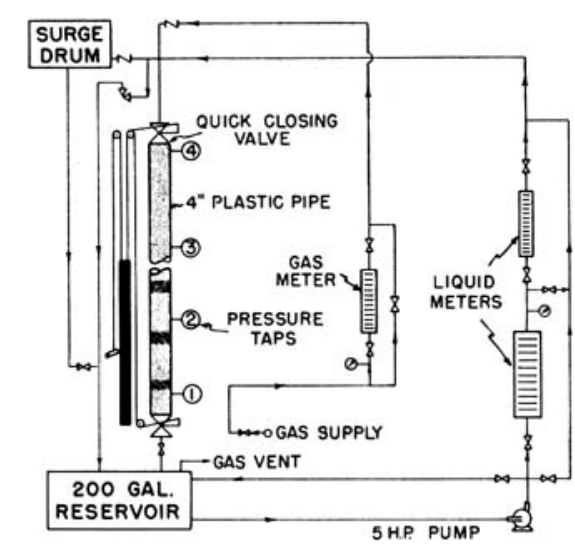

Fig. 1. Schematic diagram of experimental equipment. column and the porosity of the packing material.

The major portion of the original data was transcribed on IBM cards and processed with an IBM-650. The accuracy of the observations ranges from $\pm 3 \%$ for the rotameters to less than $0.5 \%$ for most of the manometer readings.

\section{DERIVATION OF CORRELATION RELATIONSHIPS}

The general energy balance in a flow system can be written as follows:

$$
\int \frac{d P}{\rho}+\frac{\Delta u^{2}}{2 g_{c}}-\Delta L+\Sigma F+W_{s}=0
$$

The shaft work is zero for downward two-phase flow, and the change in density over a small distance may be neglected. The kinetic energy term may also be set to zero for the velocity changes encountered. Upon integration and rearrangement Equation (4) becomes

$$
-\frac{\Delta P}{\Delta L}+\rho=\frac{(\Sigma F) \rho}{\Delta L}=\delta
$$

Equation (5) defines $\delta$. The total frictional energy $\delta$ will have the units pounds per square foot per foot, or pounds per square inch per foot when the density is given suitable units. For horizontal flow the density does not appear in Equation (5), since $\Delta L$ is zero in Equation (4). The total frictional energy is independent of orientation and is the value given by conventional single-phase pressure-drop correlations. Although Equation (5) is based on the flow of a single fluid, it was found to be adequate for twophase data when the density was interpreted as that of the actual flowing mixture in the packed bed.

During two-phase concurrent flow in a packed bed each phase can be thought of as flowing in a bed restricted by the other phase. The effective porosity for one phase is reduced by the presence of the second phase. The two-phase friction loss may then be written in terms of the single-phase flow of liquid in a restricted bed. The Reynolds number for the liquid may be defined as

$$
N_{R e_{l}}^{\prime}=\frac{D_{p} u_{\imath} \rho_{l}}{\mu_{l}\left(\varepsilon R_{l}\right)^{n}}
$$

The term $R_{\imath}$ will be recognized as the liquid saturation previously defined. The product $\boldsymbol{\epsilon} \boldsymbol{R}_{\boldsymbol{l}}$ is interpreted as the effective porosity for the liquid phase in the restricted bed. The definition of Reynolds number is of the same form as that used by Brownell and Katz (2) 


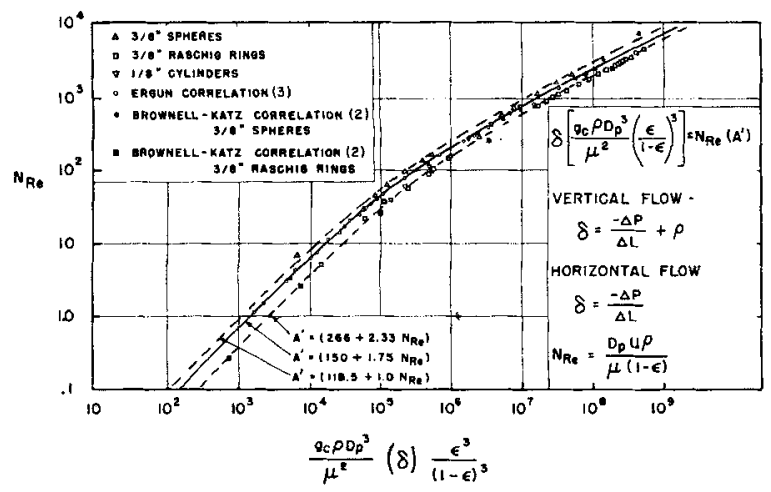

Fig. 2. Single phase pressure drop in packed beds.

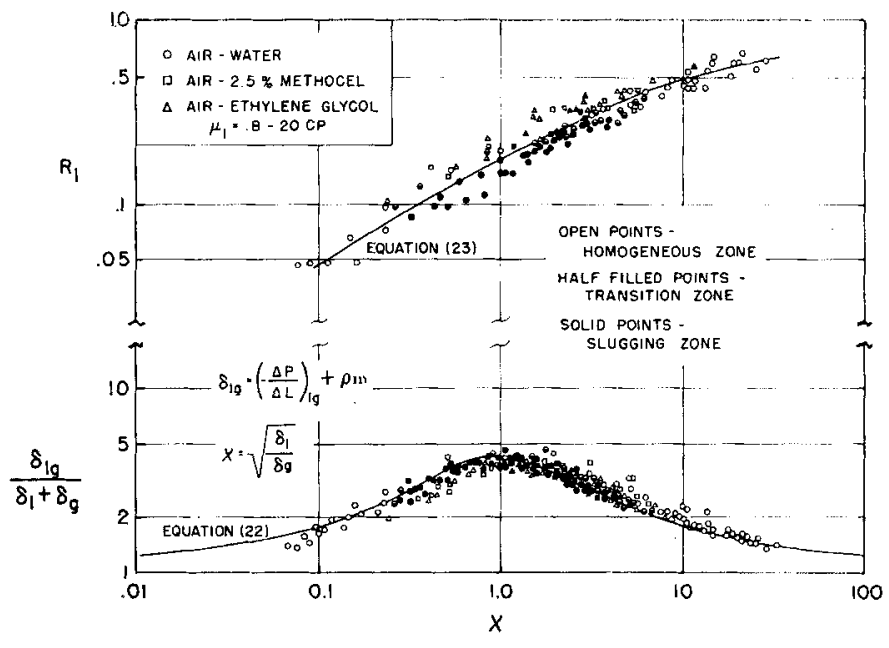

Fig. 3. Data on $3 / 8$-in. Raschig rings. in correlating single-phase friction loss. The Fanning form of the friction factor leads to the expression of the total two-phase frictional loss as

$$
\delta_{l g}=\frac{2 f_{l} \rho_{l} u^{2}}{\left(\epsilon R_{l}\right)^{m} D_{p} g_{c}}
$$

The friction factor for the liquid may be expressed in the general Blasius form as suggested for two-phase flow in pipes by Lockhart and Martinelli (6). Expressing the friction factor for the liquid in the Blasius form one gets

$$
f_{i}=\frac{C_{\imath}}{\left(N_{R e^{\prime} l}\right)^{s}}==\frac{C_{l}}{\left[\frac{D_{p} u_{\imath} \rho_{l}}{\mu_{l}\left(\epsilon R_{l}\right)^{n}}\right]^{e}}
$$

Substitution of Equation (8) for $f_{l}$ in Equation (7) results in

$\delta_{l g}=C_{l}\left[\frac{\mu_{l}\left(\epsilon R_{l}\right)^{n}}{D_{p} u_{l} \rho_{l}}\right]^{s}\left[\frac{2 \rho_{l} u^{2}}{\left(\epsilon R_{l}\right)^{m} D_{p} g_{c}}\right]$

The collection of $\boldsymbol{R}_{\boldsymbol{l}}$ terms in Equation (9) gives

$\delta_{l g}=C_{l}\left[\frac{\mu_{l} \epsilon^{n}}{D_{p} u_{l} \rho_{l}}\right]^{s}\left[\frac{2 \rho_{l} u^{2}{ }_{l}}{\varepsilon^{m} D_{p} g_{c}}\right] R_{\imath}^{(n+-m)}$

The first two terms in Equation (10) represent the friction factor for the liquid flowing in the unrestricted bed, since $n$ and $s$ depend only on the packing material and the mode of flow. The first three terms will then be recognized as the friction loss for the liquid flowing alone in the unrestricted bed with effective porosity $\epsilon$ at the superficial rates and conditions of the two-phase flow. Equation (10) may be rewritten as

$$
\delta_{i g}=\delta_{l} R_{t}^{(n s-m)}
$$

The development shown for the liquid phase can also be carried out for the gas to show the relationship between two-phase friction loss and the singlephase loss for the gas flowing alone in the bed at the conditions of the twophase flow. The result is

$$
\delta_{t_{g}}=\delta_{g}\left(1-R_{\imath}\right)^{(n-m)}
$$

Equations (11) and (12) relate the two-phase friction loss to the singlephase losses and the liquid saturation for a given packing and mode of flow. The single-phase losses $\delta_{l}$ and $\delta_{g}$ can be calculated from established correlations, but the liquid saturation is unknown in the design calculation. Manipulation of Equations (11) and (12) leads to

$$
\begin{aligned}
& \frac{\delta_{l o}}{\delta_{l}+\delta_{\theta}} \\
& =\frac{1}{R_{l}{ }^{(m-n s)}+\left(1-R_{l}\right)^{(m-n s)}}=F_{1}\left(R_{l}\right)
\end{aligned}
$$

and

$\chi=\sqrt{\frac{\delta_{l}}{\delta_{g}}}=\left[\frac{R_{i}}{1-R_{l}}\right]^{\frac{m-s n}{2}}=F_{2}\left(R_{\imath}\right)$

$F_{1}$ and $F_{2}$ are functions of $R_{l}$ alone for a given packing and mode of flow. The variable $\chi$ is defined by Equation (14). If Equation (14) is solved for $R_{l}$ and substituted in Equation (13), the result is

$$
\begin{gathered}
R_{l}=F_{3}(\chi) \\
\frac{\delta_{l}}{\delta_{l}+\delta_{g}}=F_{4}(\chi)
\end{gathered}
$$

$F_{3}$ and $F_{4}$ are functions of $\chi$ alone for a given packing and mode of flow. The ratio of the total frictional loss to the sum of the single-phase losses, $\delta_{i g} /\left(\delta_{i}+\delta_{g}\right)$, will be termed the "two-phase parameter." The result of the derivation is summarized in Equations (15) and (16) which state that the liquid saturation and the two-phase parameter should both be functions of $\chi$ alone, for a given packing material and mode of flow. The independent variable is quite suitable for the design calculation, since it can be obtained readily from established single-phase correlations

The establishment of a correlation for two-phase concurrent flow in packed beds requires the establishment and evaluation of the functions $F_{3}$ and $F_{4}$.

\section{CORRELATION OF SINGLE-PHASE DATA}

Confirmation of the relationships suggested by the derivation requires the evaluation of $\delta_{l}$ and $\delta_{g}$ for the single-phase flow of each fluid. In order to prevent deviations in singlephase correlations from affecting the two-phase results data were obtained for most of the fluids and packings studied. The data were used to develop specific coefficients for the single-phase

\begin{tabular}{|c|c|c|c|c|c|c|c|c|}
\hline \multirow{2}{*}{$\begin{array}{l}\text { Rum } \\
\text { num- } \\
\text { ber }\end{array}$} & \multicolumn{2}{|c|}{ Reynolds number } & \multirow[b]{2}{*}{$\delta_{t g}$} & \multirow[b]{2}{*}{$\delta_{l}$} & \multirow{2}{*}{\multicolumn{2}{|c|}{$\begin{array}{l}\text { Liquid } \\
\text { satura- } \\
\text { tion, \% }\end{array}$}} & \multirow[b]{2}{*}{$\chi$} & \multirow[b]{2}{*}{$\delta_{t g} / \delta_{l}+\delta_{l}$} \\
\hline & Liquid & Air & & & & & & \\
\hline 5 & 2,739 & 0 & 2.469 & 2.467 & 0 & 100.0 & $\infty$ & 1.001 \\
\hline 23 & 1,443 & 1,058 & 2.788 & 0.7887 & 0.0767 & 32.3 & 3.205 & 3.222 \\
\hline 28 & 1,523 & 4,231 & 5.570 & 0.7857 & 0.7259 & 15.0 & 1.040 & 3.685 \\
\hline 57 & 2,401 & 700.5 & 5.860 & 3.063 & 0.0226 & 47.0 & 11.640 & 1.899 \\
\hline 63 & 2,813 & 4,155 & 10.057 & 3.042 & 0.4475 & 26.6 & 2,607 & 2.882 \\
\hline 86 & 113.0 & 1,117 & 0.4095 & 0.00755 & 0.1411 & 9.9 & 0.2313 & 2.753 \\
\hline 90 & 109.1 & 4,212 & 1.761 & 0.00769 & 1.334 & 4.8 & 0.0759 & 1.312 \\
\hline 160 & 0 & 5,530 & 1.956 & 0 & 1.938 & 0 & 0 & 1.009 \\
\hline
\end{tabular}
friction loss equation of Ergun (3). The form of the Ergun correlation is

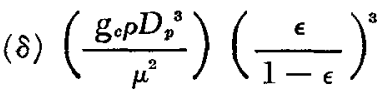

$$
\begin{aligned}
& =N_{R \theta}\left(\alpha+\beta N_{R e}\right)
\end{aligned}
$$

Table 4. Sample Calculated Results for

Water on $\mathbb{g}_{\text {g-I }}$ In. Raschig Rings in 4-In. Pipe 
and

$$
\begin{aligned}
N_{B \theta} & =\frac{D_{p} G}{\mu(1-\epsilon)} \\
D_{p} & =\frac{6(1-\epsilon)}{S}
\end{aligned}
$$

The effective particle diameter is equal to the actual diameter for spheres.

The Reynolds number and the left member of Equation (17) have been plotted in Figure 2 for the nonhydrocarbon systems on $3 / 8-i n$. Raschig rings, $3 / 8$-in. spheres, and 1/8-in. cylinders. Variation in fluid properties was satisfactorily accounted for by the dimensionless groups so that a single curve was adequate for each packing material. The data for cylinders were in agreement with the values reported by Ergun (3) for $\alpha$ and $\beta, 150$ and 1.75 respectively. For $3 / 8$-in. spheres $\alpha$ and $\beta$ were 118.2 and 1.0 , and the $3 / 8$-in. Raschig rings were correlated by $\alpha$ and $\beta$ of 266 and 2.33 respectively. The constants are summarized in Figure 2 and correlate the nonhydrocarbon data within $\pm 20 \%$. A possible entrance effect in the top section of the packed bed and a possible exit effect in the bottom section prompted the selection of the middle portion of the column as a basis for the correlation of singlephase friction loss. When all three column sections are considered, the scatter of data is less than $30 \%$.

The original Ergun correlation is represented by the solid center curve on Figure 2. The deviations from this curve are as much as $80 \%$ for all data. Figure 2 also presents a comparison of the correlation proposed by Brownell and Katz (2) with the data on spheres and Raschig rings. The deviations for this correlation are well within the experimental error, and the correlation appears to be more accurate than that of Ergun, though the form of the latter is excellent. The consideration of the sphericity of the particles allows the curves in Figure 2 to shift with the packing material in the correlation of Brownell and Katz, but such a shift is not possible with the Ergun correlation

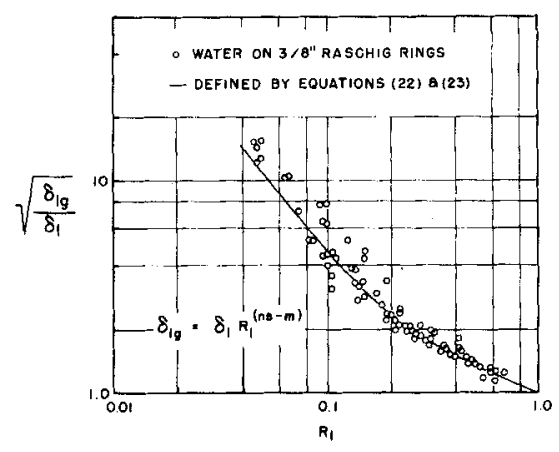

Fig. 4. Pressure drop as a function of $\boldsymbol{R}_{l}$.

as long as the constants of Equation (17) are considered independent of packing material.

It has been observed that a given packing material can be packed to give the same porosity but yield friction losses varying by as much as $50 \%$. These observations indicate that the method of packing the bed is an important variable not accounted for by any single-phase correlation yet published. Hydrocarbon data over $1 / 8$-in. cylinders were obtained in separate equipment packed in a different manner, and these data were not satisfactorily correlated by the curve of Figure 2 for nonhydrocarbon systems on $1 / 8$ in. cylinders. It is for this reason that single-phase data were desired for each packing material packed in the column as used for the two-phase studies.

\section{EXPLANATION OF TABULATED \\ RESULTS}

Table 4 is a sample of the calculated results for the data given in Table 3 on air and water over 3/8-in. Raschig rings. The Reynolds numbers for the liquid and the gas phases were calculated with Equation (18) with the mass rates in Table 3 . The total frictional loss for the two-phase flow is the corrected pressure drop per unit length as defined by Equation (5), or

$$
\delta_{l y}=-\left(\frac{\Delta P}{\Delta L}\right)_{l g}+\rho_{m}
$$

The density term $\rho_{m}$ is that of the flowing mixture at the average pressure in the column section. It can be shown that the use of the arithmetic average of terminal pressures to calculate densities for Equations (17) and (20) produces the correct average friction loss for a section (4). The value of $\Delta P / \Delta L$ was corrected for the unequal manometer legs by reducing the pressure drops in Table 3 by the pressure equivalent to a foot of the liquid phase before substitution in Equation (20). The density of the flowing mixture is given by

$\rho_{m}=\rho_{l} R_{l}+\rho_{g} R_{g}=\rho_{l} R_{l}+\rho_{b}\left(1-R_{l}\right)$.

The single-phase losses were computed from Equation (17) with suitable constants from Figure 2. The liquid saturation, the independent variable, and the two-phase parameter are also shown in Table 4.

Single-phase data were not obtained on the hydrocarbon fluids studied. Values were calculated from Ergun's original constants in the original work, but values of $\alpha$ were later obtained by extrapolating two-phase data to a zero rate for one phase. The value of $\alpha$ thus obtained was then used to adjust the original single-phase values.

\section{PRESENTATION OF CORRELATED DATA}

Two-phase data on $3 / 8$-in. Raschig rings are shown in Figure 3. The liquid saturation and the two-phase parameter $\delta_{l g} /\left(\delta_{l}+\delta_{g}\right)$ have been plotted vs. the independent variable $\chi$ as suggested by Equations (15) and (16). The two-phase parameter is seen to be a well defined function of $\chi$. The liquid saturation is also seen to be a function of $\chi$, though the scatter of data is slightly greater. The data plotted are for air with water, ethylene glycol, and a 2.5 weight $\%$ solution of Methocel in water. The liquids had viscosities ranging from 0.8 to 20 centipoise at the conditions investigated. The points shown in Figure 3 have been coded to indicate the type of flow. Open points are for the homogeneous mode of flow, half-filled points for the transition zone, and solid points for the slugging mode of flow. Three important points

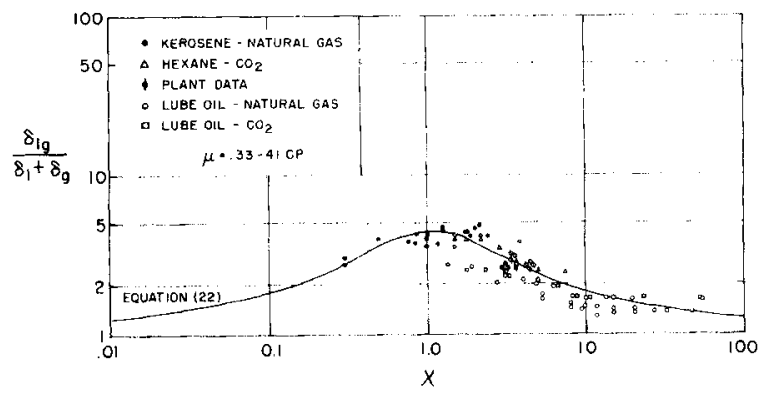

Fig. 5. Dato on 3/8-in. spheres.

Fig. 6. Data on $1 / 8$-in. cylinders and 3-mm. spheres. 
are established by these data on Raschig rings. The two-phase parameter and the liquid saturation are both well correlated by $x$, the correlations are not significantly affected by changes in viscosity, and the three modes of Hlow are correlated by the same curve.

Another of the derived relationships can be illustrated by the Raschig ring data. Equation (11) states that the two-phase friction loss should be a function of the single-phase loss for the liquid and the liquid saturation to a power dependent upon the mode of flow for a given packing. The square root of the two-phase loss over the single-phase loss has been plotted vs. $R_{\imath}$ in Figure 4 to test Equation (11). Data for water and air over Raschig rings have been plotted, and the relationship implied by the curves of Figure 3 has been used to determine the solid curve in Figure 4. Equation (11) is confirmed, since there are two relatively straight lines on the log-log plot to indicate that the exponent assumes two constant values. A change in exponent corresponding to the shift from laminar to turbulent flow was to be expected. The definite relationship in Figure 4 follows directly from the successful correlation of data in Figure 3, but the two straight portions of Figure 4 further confirm the assumptions upon which the derivation was based.

The correlation suggested by Equations (15) and (16) has now been established for a given packing material: namely $3 / 8-$ in. Raschig rings. Data for a second packing are plotted in Figure 5. The data plotted were obtained on $3 / 8-i n$. spheres which have properties quite different from those of the Raschig rings. The curves drawn on Figure 5 are identical with those of Figure 3 , as are the scales and variables plotted. The fluid systems are air with water and air with ethylene gly$\mathrm{col}$, and the range of fluid viscosities is the same as that of Figure 3 . The significance of these data is that the same curves which correlate the data for $3 / 8-i n$. Raschig rings also correlate the data on $3 / 8$-in. spheres.

To further establish the generality of the two-phase correlation, friction-loss data on five hydrocarbon systems and two additional packing materials are shown in Figure 6. The curve is identical with that of Figures 3 and 5 . The two packing materials are $1 / 8-$ in. catalyst cylinders and $3-\mathrm{mm}$. glass beads. The systems included are kerosene with natural gas, hexane with carbon dioxide, lube oil with natural gas, lube oil with carbon dioxide, and plant data from a hydrofiner processing a heavy oil fraction with a hydrogen rich gas. The plant data were obtained from a large diameter bed operated at elevated temperatures and pressures. The hydrocarbon systems were studied in a separate piece of experimental equipment from that used to obtain the data in Figures 3 and 5. A 2-in. diam. column was used in these experiments, but no liquid saturation data were obtained for the systems included. The wide range of liquid viscosities and fluids correlated strongly support the form of Equations (15) and (16).

Figure 7 summarizes all two-phase data and the final proposed correlation of liquid saturation and friction loss. The scales, variables, and curves are the same as those of Figures 3, 5, and 6 . Eight fluid systems and four packing materials are included. The dotted curves in Figure 7 are the $\pm 20 \%$ limits on the liquid saturation and friction loss correlations. Some $87 \%$ of the values of $\delta_{i g} /\left(\delta_{t}+\delta_{g}\right)$ lie within $\pm 20 \%$ of the correlating curve; the remaining $13 \%$ lie well within $40 \%$ of the curve. Over 600 data points are represented, though many lying near the curve have been omitted for clarity. The standard deviation of the friction loss data is $13 \%$, and the errors are those which would occur in the design calculation or the back calculation of the observed data.

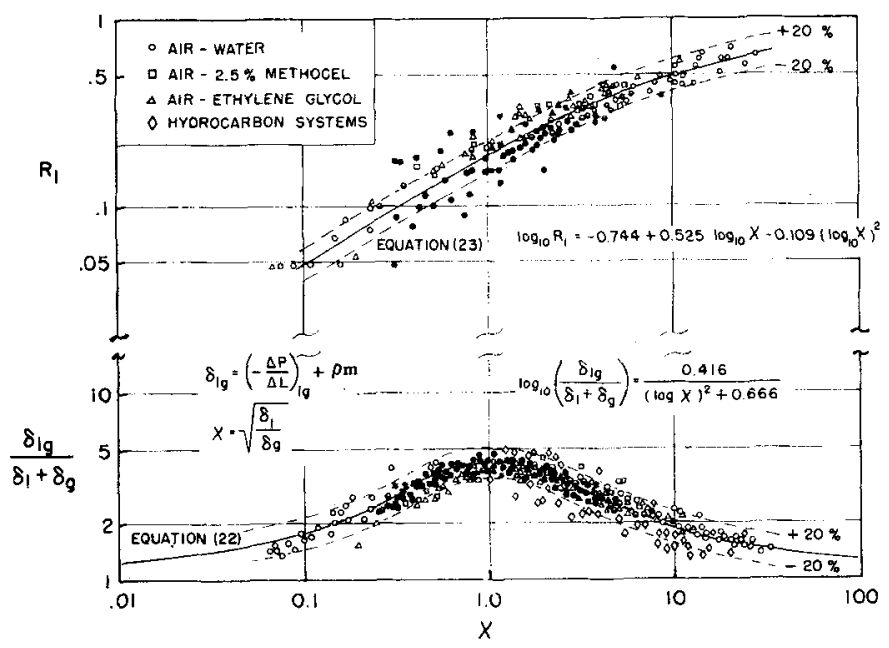

Fig. 7. Summary of two-phase data.
The accuracy of the liquid-saturation data is not as good as that of the friction-loss data. Still $80 \%$ of the data fall within $20 \%$ of the correlating curve. The standard deviation is $16 \%$ for the liquid-saturation data.

The symmetry of the friction-loss curve permits the fitting of a relatively simple equation as follows:

$\log _{10}\left(\frac{\delta_{l g}}{\delta_{l}+\delta_{g}}\right)=\frac{0.416}{\left(\log _{10} \chi\right)^{2}+0.666}$

The liquid-saturation data has also been fitted by the power series

$$
\begin{aligned}
\log _{10} R_{\imath}= & -0.774+0.525\left(\log _{10} \chi\right) \\
& -0.109\left(\log _{10} \chi\right)^{2} \quad(23)
\end{aligned}
$$

for $0.05<x<30$. The curves of Figures $3,5,6$, and 7 were constructed from Equations (22) and (23), and the equation numbers have been shown as references to indicate the fact that all curves are the same.

Some properties of the friction-loss and liquid-saturation correlations are of interest. To be compatible with single-phase flow relationships the two-phase friction correlation must reduce to the single-phase loss for one phase as the rate of the other approaches zero. When the flow of liquid is reduced to zero, $\delta_{l}$ and $\chi$ approach zero as seen from their definitions. As $\chi$ approaches zero, the two-phase parameter approaches unity and reduces to the necessary relation that the two-phase loss becomes equal to the single-phase gas loss. A similar result is obtained by setting $\chi$ and $\delta_{\imath}$ to zero

Table 5. Range of

Expertmental Variables

$\begin{array}{lll}\text { Variable } & \text { Mini- } & \text { Maxi- } \\ \text { mum } & \text { mum }\end{array}$

Column size, in. $\quad 2 \quad 4^{\circ}$

Packing diameter, in. $1 / 8 \quad 3 / 8$

$\begin{array}{lll}\text { Packing porosity } & 0.357 & 0.520\end{array}$

Superficial gas velocity,
ft. $/$ sec.

Superficial liquid ve-

locity, ft./sec. 0

Viscosity of gas, centipoise

Viscosity of liquid, centipoise
Reynolds number for

Reynolds number for 0
gas Reynolds number for
liquid

Two-phase pressure drop, lb./sq. in./ft. 0.24

Column pressure, ib./ sq. in. gauge 2.8

Fraction liquid 0

0.012

0.019

- Also commercial column several feet in diameter. dred $\mathrm{lb} . / \mathrm{sq}$. in. gauge. 


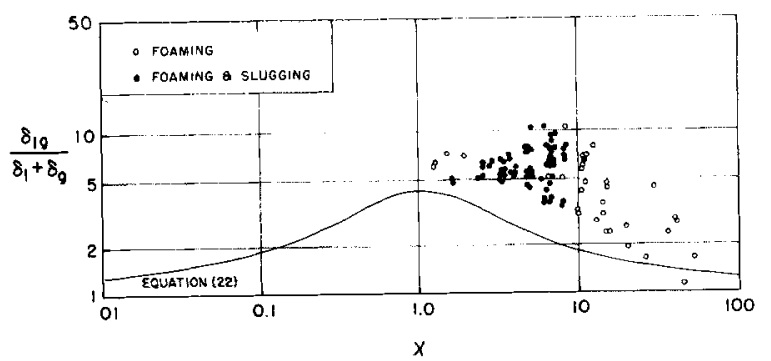

Fig. 8. Two-phase data on foaming systems.

in Equation (22). Similar behavior is observed for single-phase liquid flow when the single-phase gas loss becomes zero and $x$ approaches infinity. The two-phase parameter must again approach unity. Figure 7 confirms that the experimental values of the two-phase parameter approach unity smoothly as $\chi$ approaches both zero and infinity. The correlation of liquid saturation must also conform to some consistency checks. When $x$ becomes infinite, for single-phase liquid flow, the liquid saturation must approach 1 . When $\chi$ becomes zero for single-phase gas, the liquid saturation must approach zero. Both consistency checks are met by the data of Figure 7 . Equation (22) exhibits all properties of the friction loss correlation and may be extrapolated freely, but Equation (23) is a power series fit which is only good within the limits given.

The form of the correlation is such that the range of the pressure drops, Reynolds numbers, viscosities, and other variables cannot be determined by looking at the correlating plot. The parameter $\chi$ expresses the ratio of energy losses for the liquid and gas phases, but it says nothing about their absolute values; the same applies to the two-phase parameter $\delta_{l g} /\left(\delta_{l}+\delta_{g}\right)$. There are many sets of friction losses which plot as the same value of $\chi$, and the curves of Figure 7 have been traversed many times at different pressure-drop levels. Table 5 summarizes the maximum and minimum values of the major variables and parameters studied.

It was pointed out that the usual single-phase correlations for friction loss are independent of orientation. The two-phase correlation is also expected to hold for true concurrent flow for both horizontal and upflow cases. No significant change in the liquid-saturation correlation is expected with orientation at very high rates. But since the correlation was not found to depend upon rate for the downflow problem, no change is expected in the saturation correlation with either rate or orientation when true concurrent flow is maintained. Therefore the use of the proper energy balance with the proposed liquid-saturation and fric-

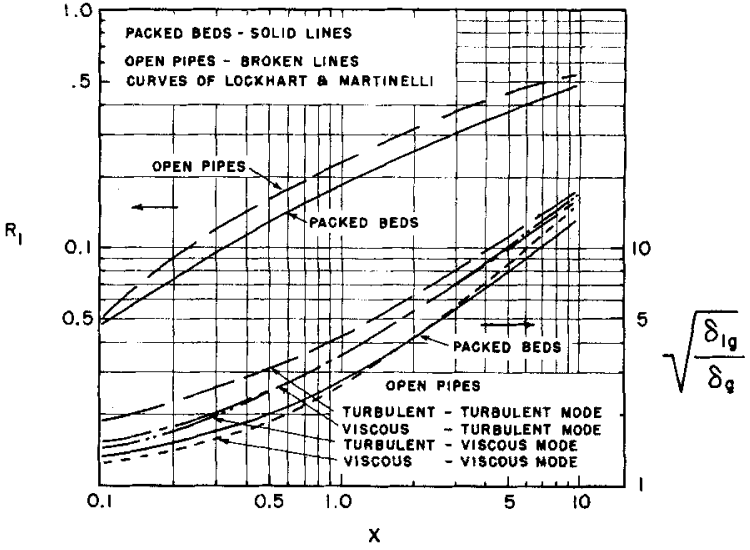

Fig. 9. Comparison with flow in pipes.

tion-loss correlations is expected to give good results for any orientation.

\section{EFFECT OF FOAMING ON PRESSURE DROP}

The data and correlations which have been presented are based on nonfoaming systems or on foaming systems with foam breakers added. The data points shown in Figure 8 were obtained from foaming systems to illustrate the large deviations which may be expected when foaming occurs under flowing conditions. The nonfoaming correlation curve serves as a basis for comparison. The observed values of the two-phase parameter are as much as five times the value predicted by the nonfoaming correlation. Figure 8 is not an attempt to correlate foaming data, but it does point up the need for a better understanding of the mechanism of foaming which would permit the correlation of such data. The plot may be of further qualitative value in determining the existence of foaming conditions within equipment by noting large deviations from the nonfoaming correlations. The complete data on foaming systems obtained on Methocel and soap solutions and on hydrocarbon systems have been recorded in the hope that a better understanding of foaming may make their correlation possible (4). Five general observations on foaming may be made as follows:

1. Foaming produces much greater effects in smaller particle diameter beds. The mild foaming of Methocel solutions in $3 / 8$-in. Raschig rings had negligible effect.

2. The emulsification of gas in the liquid phase is more severe in smaller packings, and the liquid saturation is consequently reduced.

3. The effect of foaming on friction loss becomes smaller as the rates arp increased and the pressure drop rises to higher levels. The foaming forces eventually become smaller than the frictional forces, and their effects seem to be lost. The level of pressure drop at which foaming may be neglected varies with the fluid system and packing diameter.

4. In order to correlate the behavior of foaming mixtures some correlation must be developed for the amount of foaming as a function of the shearing and mixing of the liquid and gas phases.

5. The addition of a foam breaker reduces the effect of foaming on friction loss even though some emulsification may still occur.

A correction of the parameters by consideration of the amount of emulsification was attempted with little success. The emulsification of gas in the liquid clearly expands the liquid phase and decreases its density, but corrections of this type are an order of magnitude smaller than the deviations observed. Surface tension was not found to have an effect in the correlation of nonfoaming data. Since surface tension is known to have an important effect on foaming characteristics, values have been reported with the foaming hydrocarbon systems (4). The history of a foaming system was also found to be an important variable.

\section{COMPARISON WITH CORRELATION FOR OPEN PIPES}

A comparison of the correlation for packed beds with the correlation presented by Lockhart and Martinelli (6) reveals a remarkable agreement with the curve obtained for the the viscous-viscous mode in open pipes. The agreement between the liquid saturation curves for beds and pipes is within the error of these curves. These comparisons are made in Figure 9 , which shows the four mechanisms for open pipes along with that of packed beds on the coordinates suggested by Lockhart and Martinelli.

The fact that the data of packed beds falls on a single curve is probably 
due to the excellent mixing and distribution obtained in the vertical packed column. The excellent mixing may also account for the smaller scatter in the data for packed beds. The agreement between the liquidsaturation data may actually be closer than drawn, since Lockhart and Martinelli (6) report that their saturation measurements are probably high.

The agreement between the correlations for packed beds and open pipes suggests several conclusions. The data on open pipes were for horizontal flow, while those for packed beds were for downflow. The expected applicability of the packed-bed correlation to other orientations is therefore strengthened. Further, a uniform transition appears plausible for increasing porosities reaching to $100 \%$. The completely reduced form of the correlations seems to account adequately for all properties of the bed or pipe and the fluid systems through the use of the singlephase relationships.

\section{USE OF THE NONFOAMING CORRELATION}

An outline for a typical design calculation has been given below. Steps have been listed for the calculation of two-phase pressure drop and liquid saturation for downflow of liquid and gas when rates, inlet pressure, inlet temperature, bed length, and bed properties are given.

1. The calculation of the singlephase friction loss for the gas requires a knowledge of the average pressure in the packed section. If the bed is of great length or the friction loss is large, the bed should be broken into smaller sections. The average column pressure must be assumed and then confirmed by the calculation.

2. Calculate the single-phase friction losses from any established correlation. If it is desired to use the Ergun equations, calculate the Reynolds number for each phase from Equation (18) by means of the mass rate of the single phase and the total porosity of the bed. Then compute the single-phase friction loss for each phase from Equation (17) with suitable constants from Figure 2.

3. Calculate the value of $\chi$ and $\delta_{l g} /\left(\delta_{l}+\delta_{g}\right)$ from Equations (14) and (22). The two-phase friction loss can then be calculated with the aid of the single-phase losses.

4. Calculate the liquid saturation from Equation (23) and the density of the flowing mixture from Equation (21).

5. Calculate the two-phase pressure drop from Equation (20) and check the assumed average pressure to complete the problem.

\section{CONCLUSIONS}

This paper presents a correlation of two-phase friction loss for downward How in vertical packed beds and of the liquid saturation accompanying the two-phase flow. A wide range of data from two pieces of experimental equipment and a commercial unit have been correlated with a standard deviation of $13 \%$ on friction loss and $16 \%$ on liquid saturation.

The design calculation can be made from the knowledge of single-phase friction losses for the gas and the liquid when they flow alone in the bed. This knowledge may come from any established single-phase correlation or from experimental data. The use of the single-phase friction losses satisfactorily characterizes the packing material and fluid properties so that these variables do not appear directly in the two-phase correlation.

The friction loss and saturation correlations are expected to hold for any orientation of the bed so long as true concurrent flow is maintained. The pressure drop may be obtained from the predicted friction loss through the proper energy-balance relation based upon orientation.

\section{NOTATION}

$A^{\prime} \quad=$ function of Reynolds number, $\left(\alpha+\beta N_{R e}\right)$

$C=$ constant dependent upon packing and mode of flow

$D_{p}=$ characteristic diameter of packing material

$f=$ friction factor for singlephase flow

$F_{1}, F_{2}=$ functions of liquid saturation

$F_{3}, F_{4}=$ functions of $\chi$

$g_{c}=$ conversion factor, 32.17 pdl./ lb.-mass in English units

$G \quad=$ mass velocity based on unpacked flow area, [(lb.mass)/ (min.) (sq.ft.) ]

$L=$ linear dimension measured downward

$m$ = exponent dependent on packing material

$n=$ exponent dependent on packing material

$P \quad=$ absolute pressure, [(lb.force)/ (sq.ft.) or (lb.force)/(sq.in.)]

$\Delta P / \Delta L=$ pressure drop per unit length, [lb.-force/sq.in./ft., (lb. force) $/(\mathrm{sq} . \mathrm{ft}$.) (ft.) or (lb. force)/ (cu. ft.)]

$R$ = fraction of void volume occupied by a phase, saturation

$N_{R e}=$ modified Reynolds number, $\left(G D_{p}\right) /(\mu)(1-\epsilon)$

$N_{R e^{\prime}}=$ Reynolds number, $\left(D_{p} u \rho\right) /$ $(\mu)(\epsilon R)^{n}$

$S=$ surface area of packing per unit volume, (sq.ft./cu.ft.) $s \quad=$ exponent dependent on packing and mode of flow

$u=$ superficial velocity in open column, (ft./sec.)

$W_{s}=$ shaft work, (ft.-lb. force/lb. mass)

\section{Greek Letters}

$\alpha, \beta=$ constants in single-phase friction loss correlation

$\delta=$ total energy to overcome friction, $(-\Delta P / \Delta L)$ for horizontal flow, or $(-\Delta P / \Delta L)+\rho$ for vertical flow

$\epsilon=$ fraction voids in packing, (void volume/unit volume of column)

$\mu \quad=$ viscosity, (lb. mass/ft.-min.)

$\rho \quad=$ density, (lb. mass / cu. ft.)

$\Sigma F=$ energy converted to friction, (ft.-lb. force/lb. mass)

$\varphi_{\imath}=\sqrt{\delta_{l g} / \delta_{l}}$

$\varphi_{0}=\sqrt{\delta_{l g} / \delta_{g}}$

$\chi=\sqrt{\delta_{l} / \delta_{g}}$

\section{Subscripts}

$g=$ gas phase, on $\delta$ or $\Delta P / \Delta L$ in dicates the value calculated from single-phase correlations for the gas flowing alone in the bed at the same temperature and pressure as the twophase case

$l=$ liquid phase, on $\delta$ or $\Delta P / \Delta L$ indicates the value calculated from single-phase correlations for the liquid flowing alone in the bed at the same temperature and pressure as the twophase case

$\lg \quad=$ liquid and gas phases flowing simultaneously and concurrently

$m$ = flowing mixture of gas and liquid

\section{LITERATURE CITED}

1. Baker, Ovid., Oil Gas J., 56, No. 45, p. 156 (Nov. 10, 1958).

2. Brownell, L. E., and D. L. Katz, Chem. Eng. Progr., 43, 537 (October, 1947).

3. Ergun, Sabri, ibid., 48, 89 (1952).

4. Larkins, R. P., Ph.D. thesis, Univ. Mich., Ann Arbor (1959).

5. "Industry Program of the College of Engineering," No. 369, Univ. Mich., Ann Arbor, Michigan (1959).

6. Lockhart, R. W., and R. C. Martinelli, Chem. Eng. Progr., 45, 39 (January, 1949).

7. Martinelli, R. C., L. M. K. Boelter, T. H. M. Taylor, E. G. Thomsen, and E. H. Morrin, Trans. Am. Soc. Mech. Engrs., 66, 139 ( 1944).

8. Martinelli, R. C., J. A. Putnam, and R. W. Lockhart, Trans. Am. Inst. Chem. Engrs., 41, 681 (1945).

9. Piret, E. L., C. A. Mann, and T. Wall, Jr., Ind. Eng. Chem., 32, 861 (1940).

Manuscript received June 22, 1959; revision received June 7,$1960 ;$ paper accepted June 8 ,
1960 . Paper presented at A.I.Ch.E. San Francisco meeting. 